\title{
To listen is to be...
}

\section{It is through listening that we are loved and we love... Anon}

I recently listened to a patient describe increasing levels of breathlessness in a very precise manner. He could now ascend only three flights of office stairs before feeling breathless whereas he could do seven floors earlier without breaking a sweat. He could now cover the morning walk between his home and the bus station in 8 minutes whereas the same distance had taken him less than 5 minutes all his adult life. After a good examination that involved careful cardiac auscultation followed by an echocardiogram, this gentleman turned out to have valvular rheumatic heart disease that had remained asymptomatic and undetected in the four decades of his existence. The mother of another young patient who was recently diagnosed to have severe immunodeficiency did not want to go back to the infectious diseases specialist whom they had been consulting. When I enquired about the reason - "She just doesn't listen!"

These events set me thinking on the powerful role of careful listening in the interaction between a doctor and patient. Breathlessness was the former patient's third complaint, after more recent but nondescript fever and cough. It just happened that he met me on a non-working day when the outpatient was devoid of other patients. There were no research assistants and sundry other subordinates vying for attention in the periphery of my vision, along with the patient sitting across the table. It was a day when I was able to listen to him without feeling the enormous pressure of having to attend to 60 others who were waiting in a crowded area. I listened to him without repeated interruptions. I did not curtail my history taking to only eliciting affirmatives or negatives to a few directed questions. On another day, it is likely that I would have prescribed a cough syrup or an antibiotic and sent him away. Or requested a PET scan, vaguely hoping that it will show up something! This day I paid careful attention to his words with simultaneous reflection and analysis of the possible reasons for his complaints...I listened. Mercifully my fancy cell phone also did not irretrievably rupture my chain of thoughts. The result was establishment of a precise diagnosis without

\begin{tabular}{|l|l|}
\hline \multicolumn{3}{|c|}{ Access this article online } \\
\hline Quick Response Code: & Website: \\
\hline & www.jmpo.org \\
\hline
\end{tabular}

having to resort to ten unnecessary investigations.

Of course, as any wise old physician will affirm, the benefits of listening go far beyond diagnostic precision. There is nothing more valuable than attentive listening to foster a bond of trust and empathy between a doctor and patient. It conveys to one human that she is important enough for another to give five minutes of undivided attention from his existence. The resultant health benefits can only be a matter of conjecture. In this era of evidence based medicine (even though I am uncomfortable with the notion that everything can be reduced to 'evidence') I wonder whether anyone has considered conducting a randomized trial of mandated attentive listening to patients versus routine practice, to evaluate the 'hard' benefits of the former. I would like to think that attentive listening is likely to lead to fewer investigations, greater diagnostic precision, better quality of life, and perhaps even higher cure rates and survival!

The listening deficit in a doctor -patient encounter is a reflection of our times. Debates rage on primetime television with no one listening to anyone else, anchor included. I often don't listen to my young son even when I am directly looking at him...children being blessed with a heightened sense of perception, he repeats himself many times over. Questioners don't listen to the answer...the question was never intended to elicit one. Marital partners no longer have the inclination or the time to listen to each other...one of the reasons, no doubt, for the soaring rates of separation.

While others can perhaps afford the luxury of not listening, doctors cannot. But do they get an enabling environment conducive to listening and meaningful communication? Many hospitals, especially public ones, are crowded and chaotic beyond description - utterly non conducive to any communication. Doctors are tasked with impossible workloads - beyond a normal human's capacity for soaking in communication, especially one that is full of pain and suffering. This is undoubtedly one the important reasons for the widespread preference for private hospitals in our society. When patients complain that 'doctors don't have time' they often mean that 'doctors don't have time to listen'. Medical students are almost never formally educated in the art of listening and its importance. This is lamentable because humans can train themselves to listen, at least in some measure. The prevalent system of healthcare economics does not incentivize cognitive skills such as effective communication - it prefers other 'hard' activities 
such as insertion of endoscopes and getting the fanciest scans done on one's patients. There is actually not just benign neglect of communication but active hostility listening is essentially considered 'wasted' time. It is not surprising that modern physicians lay so little emphasis on careful listening and communication.

In some of the reasons for poor listening lie the solutions. The medical fraternity has to rediscover this vital element of its professional raison d'etre. It was not without reason that Mark Antony began his famous exhortation to friends,
Romans and countrymen with "lend me your ears"...we must relearn how to lend our ears to our patients.

\section{Sudeep Gupta}

Editor-in-Chief

Associate Professor of Medical Oncology Tata Memorial Hospital, Mumbai, India.

\section{E-mail:}

How to cite this article: Gupta S. To listen is to be.... Indian J Med Paediatr Oncol 2011;32:1-2.

\section{IJMPO is now in PubMed}

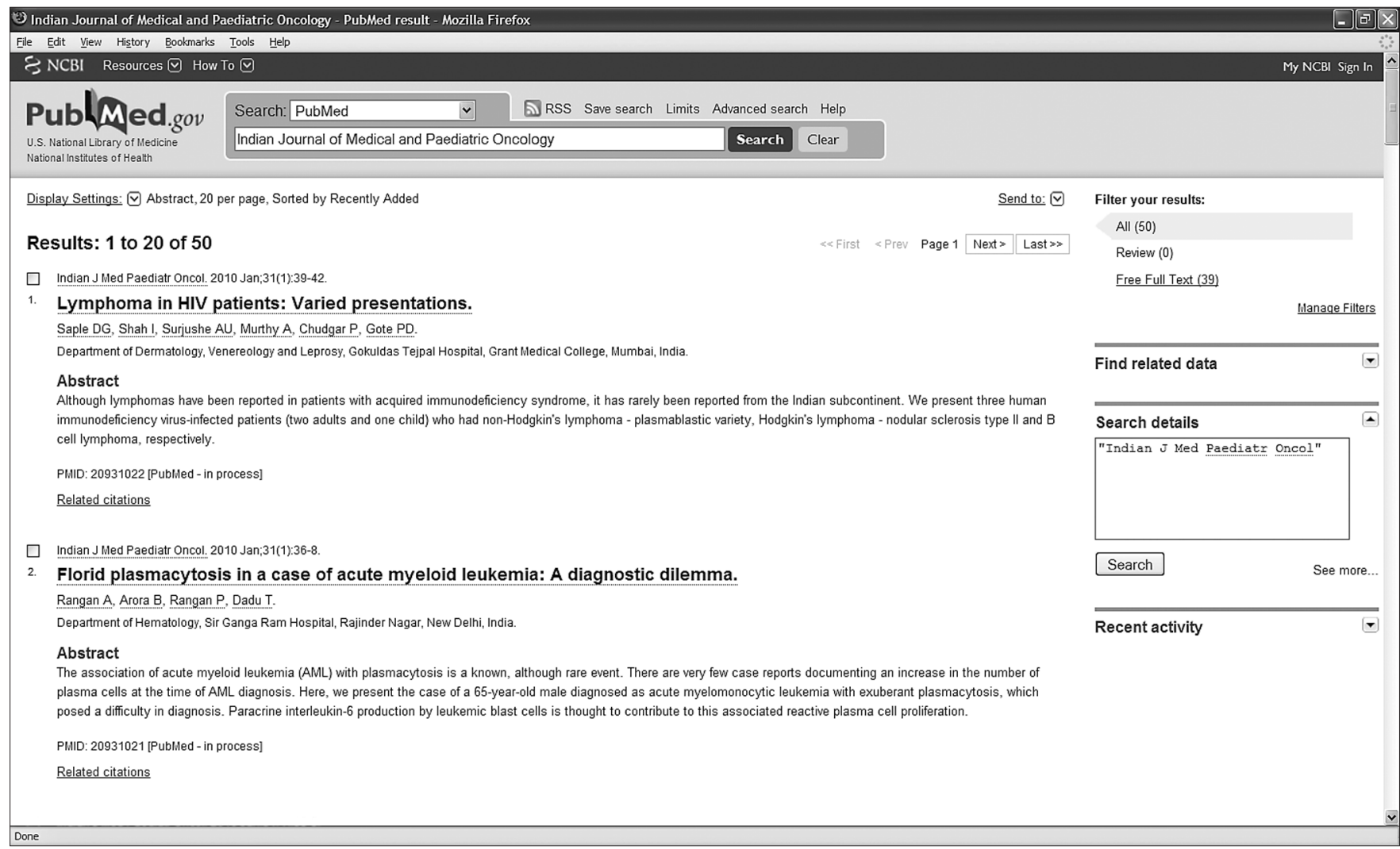

